\title{
The Value and Perfection of China's Inter-Party Consultative Democracy
}

\author{
Song Jufang \\ Teaching \& Research Dept. Beijing Institute of Socialism \\ Beijing, China \\ fangkatie@gmail.com
}

\begin{abstract}
The paper describes what China's inter-party consultative democracy is, and tries to find out the value and perfection of it. The method of real cases, comparative and systematic analysis is used to figure out the key five elements of China's inter-party consultative democracy. It's emphasized that China's inter-party consultative democracy plays a key role of maintaining the political stability, strengthening democratic supervision, promoting social harmony and other important valuable function. The author appeals to find the perfection methods by consolidating the realistic basis, enriching the democratic forms, improving the quality and supervision of consultative democracy.
\end{abstract}

Keywords-inter-party consultative democracy; element; value; perfection

China's inter-party consultative democracy is a form of democracy which Chinese Communist Party and the democratic parties have equal consultation on major state guidelines, policies and important affairs. This form of democracy is based on the carrier of the multi-party cooperation and political consultation system under the leadership of the CCP, and the basic operating principles of democratic centralism. In the practice of over 60 years, China's consultative democracy has played an irreplaceable role in the consolidation of the new regime, the completion of socialist transformation and socialist construction. The 18th Party's report pointed out that "socialist consultative democracy is an important form of democracy in china. We should perfect the consultative democracy system and working mechanism, promote the wide, multilevel, systematic development of consultative democracy. To have a broad consultation about the actual problems in the development of economic society and major issues involving the immediate interests by the channels like the organs of state power, CPPCC organizations, political parties, groups etc. and with the methods of collecting people's topics and wisdom, building consensus and enhancing the composition of forces."[1] So, it's very necessary to have an analysis on the elements, value and perfection of China's inter-party consultative democracy.

\section{THE ANNALYSIS OF THE ELEMENTS OF CHINA's INTER-PARTY CONSULTATIVE DEMOCRACY}

China's social soil not only gives birth to Chinese characteristic party system, but also gives the system a special form of democracy, that is China's inter-party consultative democracy. As an important part of Chinese characteristics socialist democracy, China's inter-party democracy has a careful element structure.

China's inter-party democracy includes consultative subject, consultative object, consultative location, consultative method and consultative result.

The consultative subject means the participants of consultation, and it means CCP and democratic parties in terms of contemporary china's inter-party democracy. Although independents don't construct a formal form of political party, because they have the character of a party, as an important sector of the CPPCC, they also belong to one of the consultative subjects. So, it can say that the consultative subjects of China's inter-party democracy include the following: (1) the consultation between CCP and democratic parties, independents, (2) the consultation between democratic parties and independents. And in this paper, it means the first.

The consultative object means the contents of the consultation. It includes national and local fundamental policy and the important issues of politics, economy, culture and social life, the common affairs of all parties participating in the work of the CPPCC, the internal affairs in CPPCC and other important issues concerning the patriotic united front.[2] Beyond the CPPCC, at the central level, it mainly includes: the important documents of the CCP National Congress and the Central Committee of the Communist Party, the proposed amendments to the constitution and laws, the recommended candidates of national leaders, the important decisions on pushing forward reform and opening-up, the medium- and long-term plan for national economic and social development, some of the major issues in relation to the whole nation, notification of important documents and important information and advice, and other important issues which need to be consulted.[3] In fact, the CCP have developed many kinds of consultation with democratic parties based on the reality.

The consultation location means the place of consulting. It includes the consultative areas and consultative agencies. For the consultative areas, it mainly includes political area and social area. It is obviously that the inter-party consultation happens in the first area. In this area, the consultation is mainly held in CPPCC and the department of United Front of CCP. CPPCC is the only political agency which democratic parties are allowed to participate in with the name of partisan. As the important sectors, CCP and democratic parties can consult the consultation object. While, one of the important responsibilities of the department of 
United Front of CCP is to organize the democratic parties to have consultation, and there is a special department working for democratic parties. So, CPPCC and the department of United Front of CCP are both the important consultative areas for China's inter-party consultation.

The consultative method means the forms and ways of consultation. China's inter-party consultative methods include the consultation between CCP and democratic parties and the consultation between them in CPPCC. For the first one, it includes the following consultative ways: CCP Central Committee invites the leaders of the democratic parties to have democratic consultation to consult the major policies which will be issued by the CCP Central Committee; from time to time, according to the situation, the main leaders of the CCP Central Committee invites the leaders of democratic parties to hold a high-level, small-scale chatting with the aim of communicating ideas and exchanging views; CCP or CCP Central Committee entrusts some agency to have meetings with democratic parties and independents, with the aim of notifying or exchanging important things, listening to the policy proposals put forward by democratic parties, or having some discussion; besides, the central committee of democratic parties can also put forward written proposals on state policies and other important issues to the CCP Central Committee.[4]For the second one, it can also include some ways, such as CPPCC plenary session, the Standing Committee meeting, the Chair meetings, the Standing Committee special meeting, forum held by the CPPCC party entrusted by the committee, the Secretary-General Conference, the specialized committee meetings, and the internal consultation meetings participated by the constituent units of CPPCC and the representatives from various sectors.[5]

The consultative result means the final aim and consensus of consultation. The subjects of China's inter-party consultation are equal, and the consultation is to reach a maximum consensus on the object. But they are not totally equal; in fact the party relationship is equal under the leadership of CCP. This is reflected in the results of the consultation by the separation between decision-making and consensus, that is, the consensus is only as an important reference for the Communist Party when they make some decisions.

\section{The VALUE OF CHINA's INTER-PARTY CONSUlTATIVE DEMOCRACY}

This kind of consultative form created by CCP and democratic parties has the important theoretic and practical value on maintaining political stability, strengthening the democratic supervision and promoting the social harmony.

\section{A. Maintaing Political Stability}

Political stability is the aim chased by any governors. Generally speaking, the items which influence political situation are mainly including: The level of organization and political maturity of participating subjects, the level of institutionalization of participation, the number and quality of participating channels, as well as participation forms and contents.[6] From these aspects, China's inter-party consultative democracy is benefit for maintaining political stability.

1) As we all know, the level of organization and political maturity of the participation subjects is very high.

2) The participation has a perfect system guarantee in China's inter-party consultative democracy.

3) The participation has an important channel for supporting. The party system in china is multi-party cooperation and political consultative system. China's inter-party consultative democracy is based on the carrier of it, as an important channel for our people to have their power of being the host and hostess.

4) The consultative forms and contents have the characteristics of consultative and public nature. The party's political participation lying in the inter-party consultation is the consultative nature; the consultation contents are important issues about people's livelihood, so it is the public nature.

So, these elements make China's inter-party consultative democracy have the value of maintaining political stability.

\section{B. Strengthening the Democratic Supervision}

China has faced a lot of problems about power running when it is in the transitional period The formal premier Wen Jiabao has concluded these problems systematically, such as, the specification of power legal system is not perfect, the phenomenon of laws impotency, lax enforcement and impunity still exists; the problems of collusion between officers and businessman, trade between money and power, abuse of administrative power are very serious, major cases of corruption occur repeatedly, the illegal behavior of a few leading cadres, especially senior cadres of discipline have bad effects. Some problems which do harm to people's benefits are not fundamentally solved. Many people have practical difficulties in looking for good doctors, going to high qualified school, having the basic life insurance, etc. Some places and departments are in violation of the rule of building or ornamenting the government buildings, showing off, pomp for extravagance and waste, the wind of luxury is popular, the post consumption is neither standard nor transparent, the administrative cost is high.[7] There are many ways to standardize political power, but for the consultation democracy theorists, 'only the consultation can standardize and construct modern public administrator. Because the real public administrator needs the maximum publication, equality and inclusiveness when discussing and making decisions, all participants of policy consultation have the equal chance to decide issues, discuss evidences and form agendas'.[8] That is to say, the public power can run in the sunshine only by consultation.

In china, $\mathrm{CCP}$ is the only long-ruling party. Plenty of our cadres are in the leadership. In china, who has the qualification to make a big mistake? It is the CCP. The effects are very serious.[9] So the supervision should be strengthened. There are many supervision methods for ruling party, 'the democratic people outside CCP can provide a kind of supervision which can't be provided easily by party members of CCP, they can find out some mistakes and shortcoming which we haven't found out when we work, 
they can do some help for our job.'[10] As a kind of political supervision, the consultative supervision of participating party has great priority on standardizing political powers.

- The supervision subjects have obviously intelligence and psychological priority. They have rich culture knowledge and keen observation, can find out the problem at the first time, so that we can prevent it from happening; they have strong analyzing abilities, can easily grasp the nature of problems; they have strong abilities of studying, can find out the key of problems, so that they can put forward the solving proposals. They are trusted by people, can easily grasp information; they are trusted by the ruling party, and can be accepted by the party when supervising them; on the basis of the trust by the ruling party and people, they can easily solve the conflicts when participating and discussing politics.

- As the participating party, they have the ID priority. They can not only look at the issues from the different perspective as CCP, which is good for grasping the conflicts, but also participate and discuss politics directly, have frequent contact with all levels of leading cadres, so that they can supervise directly.

- As the consultative subject of inter-party consultative democracy, the participating parties have the time and effects priority. They participate in and discuss politics directly, sometimes they participate in the national supervision directly, have smooth supervision channel, can reflect problems quickly, consult with the name of democratic parties, form the mass power and have some kind of authorities which are good for solving problems quickly.

- Consultative supervision has the priority of space. In the case of the organization structure of democratic parties, there are central and local organizations; the members are widely distributed in economic, cultural and social area, showing a multi-line nature. In the case of the consultative supervision area, there are National People's Congress and local people's congresses, CPPCC central and local levels, showing a multi-level nature. So a criss-cross network supervising system is formed, it is much closer with the development of the democratic parties, it is helpful to eliminate the blind spot of supervision work.[11] It can be seen that the inter-party consultative democracy can strengthen the national democratic supervision and regulate the operation of political power better.

\section{Promoting the Social Harmony}

The most important thing of building the harmonious society of socialist is to coordinate the social interests' relationship because the harmony of social interests' relationship is the base of social harmony. To coordinate the social interests' relationship includes 3 aspects: (1) to express social interests, (2) to colligate social interests, (3) to respond to social interests.
China's inter-party consultative democracy is good for promoting social harmony by coordinating social interests' relationship: (1) it is good for expressing social interests. Specifically speaking, one is the inter-party consultative body can express the social interests through the contacting members of society; (2) the contemporary China's inter-party consultation stick to the policy that seeking common ground while reserving differences. It can not only reflect the common aspiration of the majority, but also absorb the reasonable requirements of the minority. Meanwhile it can not only listen to the supporting views, but also tolerate the voice of criticizing, which can better express the interests of the masses.

Secondly, the inter-party consultative democracy is benefit for colligating social interests. The express of the requirements of social interests is usually decentralized and partial, and it is impossible to response to everyone. So it needs to analyze and colligate those social interests' requirements. The China's inter-party consultative democracy is good for it. One is CCP and the democratic parties can analyze and colligate the interests' requirements by their contacting social members, two is CCP and the democratic parties can realize more high level and more comprehensive social interests colligating.

What's more, the inter-party consultative democracy is good for responding social interests. Besides expressing, analyzing and colligating social interests, it is necessary to respond it according to the importance when coordinating social interests' relationship. The key to respond social interests is to pay attention to people's interests and to satisfy their reasonable interests as much as possible. The inter-party consultative democracy is good for realizing it. According to consultation of the important issues which people pay much attention to, CCP and democratic parties reach to common views and turn them into the decisions and policies which meet interests' requirements of people.

\section{THE PERFECTION METHODS OF CHINA'S INTER-PARTY CONSULTATIVE DEMOCRACY}

The China's inter-party consultative democracy has had a lot of successful experiences. Since any system is not perfect, there is still some areas to be improved in China's inter-party consultative democracy. In the aspect of actual operation running, the effectiveness of China's political consultation is far from the ideal state of system as which is designed and expected. There are a lot of aspects to be improved in participants and the concrete consultation mechanism. The following are the 3 aspects which are thought to be improved:

\section{A. Consulidating the Realitstic Basis of China's Inter-Party Consultative Democracy}

- To consolidate the economic basis of China's inter-party consultative democracy. The first is to perfect the basic economy system in China. The second is to construct the system which can solve urban and rural economic structure gradually, to form a mechanism which can promote the regional economy to develop coordinately. The third is to 
improve the market system, and regulate market order. The fourth is to continue improving macroeconomic regulation and control, speed up the transformation of government functions. The fifth is to promote employment and the reform of the distribution system, improve the social security system. The sixth is to deepen the reform of the administrative system, improve the economic and legal system. The seventh is to strengthen and improve the leadership of the Communist Party, improve the ability to control the market economy.

- To consolidate the political basis of China's inter-party consultative democracy. The first is to further improve the system of people's congresses, fully guarantee the people's rights to be the host and hostess. The second is to develop the multiparty cooperation and political consultation system under the leadership of the Communist Party. The third is to further improve the system of regional autonomy of ethnic minority autonomous regions, giving more autonomy to them. The fourth is to improve the legal security system of human rights constantly, improve the realization degree of citizen democratic rights. The fifth is to realize the rational allocation of state power, strengthen the supervision of power. The sixth is to actively explore and deepen the reform of the cadre and personnel system. The seventh is to strengthen the democratic construction at the basic level, make regulations and protection for the autonomous system of rural villagers and city residents in the form of law. The eighth is to implement the policy of governing the country according to law, make sure the development of socialist democracy on the track of the rule of law.

- To consolidate the cultural base of China's inter-party consultative democracy. The first is to enhance the competitiveness of the socialist culture. Specifically speaking, we need to strengthen the socialist ideological and moral construction with the core of the socialist core value system, on the other hand, to promote the construction of cultural modernization. The second is to enhance the appeal of socialist culture. Specifically speaking, on one hand we should have cultural sense of mission, stick to the development goal of socialist culture, on the other hand, we should have the cultural consciousness, conform to the trend of world culture development, defend the socialist nature and the national characteristics of Chinese culture consciously, and also set up the culture and science development consciousness, grasp the regular of cultural development, make it become the lofty pursuit of all citizens. The third is to strengthen the socialist cultural innovation ability. Specifically speaking, on one hand, we must set up the consciousness of cultural innovation, on the other hand, to build the ecological environment of culture innovation, moreover, we should change the resource advantages into advantages of innovation based on Chinese rich culture resources. The fourth is to strengthen the socialist cultural communication. We should develop national culture resources taking advantage of the modern means of science and technology, and give publicity to culture life via using new media.

- To consolidate the social basis of China's inter-party consultative democracy. The first is to promote the sustainable development of economic society. For Public investment, on one hand, it needs to deal with the proportional relations of all aspects, promote the coordinated development of economic society; on the other hand, it is also needs to do what is possible and keep sustainable investment. The second is to straighten out the relationship between income and distribution, improve the social security system. We should mobilize all social resources to establish a redistribution and distribution system which is sound in the public interest to ensure the basic fair. The third is the establishment of a sound social macro-control mechanism, and the improvement of the social management capacity. We should establish a mechanism of social public opinion collection and analysis, social early warning system and emergency mechanism, we should regulate all kinds of social organization behavior, we should establish a good relationship between the Party committee and government and other social organizations and individuals. The fourth is to improve people's quality, enhance social cohesion. Through the development of legal system and performance management and service functions, ensure and realize the common interests of social members and the fundamental interests of the people, maintain social fairness and justice, form the cohesion of social value which is good for social unites.

\section{B. Enrich the Democratic Forms of China's Inter-Party Consultative Democracy}

We must enrich the democratic forms of consultation if we want to push the construction of inter-party consultative democracy. There are two kinds of meaning:

- To create new forms of consultation. Mr. Li Ruihuan said we should improve the existing political form, create new forms of political activity, make it more flexible, and develop the members' activeness better. We should strengthen the construction of the special committee, contact closely with the relevant departments, the democratic parties and social organizations, further play the basic role in participating and discussing politics.[12] Although it is for the consultative democracy of CPPCC, it is fit for the inter-party consultative democracy. In recent years, the forms are created continuously. For example, the leader of CCP Central Committee goes to the member team to have meetings and discussions every year during the Political Consultative Conference. It is a new form with usefulness, depth and good social influence when 
consulting in CPPCC, which is an important development of the consultation. For another example, in July 2005 and Sep 2006, the CPPCC National Committee held two special consultations, especially the second consultation, on the basis of summing up experiences in the 2005 special negotiation, the interactive unit was arranged, and members of the Committee had interactive communication with the leading comrades in the State Council. They have timely communication and face-to-face exchange of views. "It made a new breakthrough in CPPCC when it performs its functions." [13]

- To consider to recover and improve the political consultative forms existing in history. A representative form is the highest state conference. In history, the highest state conference was convened by the president, and the participants are mainly the National People's Congress and government leaders. In the early period, because many members of the democratic parties were in the government, more than half of the conference participants were the leaders of democratic parties. In the later period, the highest state conference were clearly stipulates the participants should include all the democratic parties and Chinese Federation of industry and Commerce, Independents, etc. So, in addition to heads of state and people in charge of government departments, the democratic parties have also sent representatives to participate. "At present, the State Council and local governments at all levels invite relevant members of the democratic parties and independents to attend the conference. It also belongs to participating and discussion politics, but it couldn't be compared with the highest state conference in the level and scale. From the viewpoint of developing political cooperation, it is a kind of innovation to make use of the forms like highest state conference creatively."[14] According to the way, we can think of recovering and perfecting at least two kinds of consultation form. One is bi-weekly forum, and the other is the joint meeting between CPPCC Standing Committee and NPC Standing Committee. We had the first one from Apr.20 to July, 1966. At that time the main leader of the central government and state council, the leaders of departments, the Supreme People's Procuratorate, and the Supreme People's Court all took part in it besides relevant people in CPPCC. The second one is a regular one from the 2nd session to the 5th session of CPPCC. Both of the two forms have got good reflection, and played great role at that time. If we can recover and perfect the two kinds of forms, it must be a creation.

\section{Improving the Quality and Effects of the Democratic Party's Participating in the Political Consultation}

Political responsibilities are the necessary safeguard of political democracy, also the basic sign of it. The political responsibilities mean any subjects which have political power must be responsible directly or indirectly for the members and the organizations which give the power. Participating in the political consultation under the leader of $\mathrm{CCP}$ is the important political response. At all level of inter-party consultative democracy, direct participants are all the leaders or representatives of democratic parties. In theory, their speech and behavior in political consultation is the speech and behavior representing their organizations. They must reflect the interest relations of the masses which the party contacts or represents in the consultative meeting, put forward valuable policy suggestions on consultative issues. They can neither publish "personal opinion", nor "immature views, opinions or advises".

So, not only the leaders or representatives of those parties who take part in the conference, but also the party organizations should have enough preparation with high political responsibility. The preparation includes necessary social investigation, party members' meetings, writing investigation reports or speeches, etc. in one or two weeks or some months. It is not only irresponsible for the inter-party consultation without such enough preparation, but also has bad effect on the consultative quality, consultative effects and the reputation and image of the parties. In reality, it exists that democratic parties deal with something hastily and temporarily. The reason is both in governing party and democratic parties. For governing party, when they organize inter-party consultation, they usually inform democratic parties temporarily. The democratic parties will find it very sudden since they don't know the topic, content, needs, deadline, etc. Under such circumstances, the leaders and representatives haven't enough time to prepare it. So it's necessary to improve the quality and effects of the inter-party consultative meeting.

The governing party should inform the democratic parties with topic, agenda, etc. ahead of time, so that they have enough time to prepare for it. Second, the democratic parties should perfect the inner mechanism of participating political consultation. They should play the role of organization with the base of consensus they have reached in their party, so that the organization and means can be guaranteed, meanwhile the personal priority and characteristics can be showed.

In the inter-party consultation, the democratic parties should prevent the following trends:

- Prevent the phenomenon which they act as audience and do nothing because of no preparation or not enough preparation;

- Prevent the phenomenon which they can't reflect the interests their party represents correctly and seriously or can't stick to putting forward the suggestion their party thinks right.

- Prevent the phenomenon which some individuals or representatives take their own interest or hobby into the consultative meeting as their party's interest requirements or value because of lacking of the effective of the inter party organizations, so that some wrong judgment or decisions could be made, or even some representatives participate in the 
inter-party political consultations as a way to gain personal interests.

In a word, the inter-party consultative democracy under the leadership of CCP is based on the law and system, meanwhile, is a kind of Chinese characteristic political democracy created by CCP together with democratic parties; it has not only the basic characteristics and value trend of modern social political democracy, but also the important practical significance. We should enrich and perfect this kind of democratic form further, so that it can serve for implementing the "moderate prosperity" program in an all-round way better!

\section{REFERENCES}

[1] Hu Jintao, "the Report of 18th National Congress of CCP", "the Collection of the Documents of the 18th National Congress of CCP", the People's Press, 2012,

[2] The Centre Literature Research Center of CCP, "the Important Documents Collection Since the 16th National Congress of CCP", the Centre Literature Research Center Press, 2008, p.262.

[3] The Office of CPPCC National Committee, the Centre Literature Research Center of CCP, "the important documents collection of CPPCC", Chinese Literature and History Press, 2009, p.763.
[4] The News Office of State Council, PRC., "the Party System in China", People Daily, Nov 16th , 2007.

[5] The Centre Literature Research Center of CCP, "the Important Documents Collection Since the 16th National Congress of CCP", the Centre Literature Research Center press, 2008, p.262.

[6] Nie Yunlin, "Political Participation and Political Stability", the Journal of CCNU,2000, Vol 1.

[7] Wen Jiabao, "Standardize Administrative Power Operation and Promoting the Anti-Corruption Work", Economy Daily, Feb. 13th, 2007.

[8] Chen Jiagang, "Introduction of Deliberating Democracy, Marxism and Reality", 2004,vol.3.

[9] "Works of Deng Xiaoping”,vol.1, people press, 1994,p.270.

[10] "Works of Deng Xiaoping", vol.1, people press, 1994,pp.224-225.

[11] Tong Qingping, "Trying to Discuss the Priority of the Democratic Supervision of Participating Parties", the Forum of Moving on, 2011,vol.11.

[12] "the Important Documents Collection Since the 14h National Congress of CCP", the People's Press,1996, p.750

[13] Niu Xuguang, "Consultative Democracy and CPPCC", Theoretical Dynamic,2007,vol.1733.

[14] Xiao Chaoran, Xiaowei, "An outline of the Contemporary China's Political Party System”, Heilongiiang People's Press, 2000,p.286. 